\title{
Antitüberküloz tedavi ile ilişkili rabdomyoliz
}

\section{Rhabdomyolysis associated with antituberculosis therapy}

\author{
Selman Unverdi ${ }^{1}$, Mevlut Ceri ${ }^{2}$, Gulay Kocak $^{1}$, Murat Duranay ${ }^{1}$ \\ 1 Department of Nephrology, Ankara Educational and Research Hospital, Ankara, Turkey \\ 2 Department of Nephrology, Pamukkale University Faculty of Medicine, Denizli, Turkey.
}

Dear Editor,

Isoniazid (INH)-induced rhabdomyolysis appears to be very rare (1-4). Herein, we present a case of therapeutic dosage INH therapy which has caused rhabdomyolysis in a patient with chronic renal disease (CKD).

A 73 year-old man with CKD was admitted to our hospital because of cough and sputum. He diagnosed active tuberculosis by defining cavitation in left upper lobe of the lung in computed tomography and Mycobacterium tuberculosis in sputum of culture. Initial laboratory findings demonstrated BUN $78 \mathrm{mg} / \mathrm{dL}$, creatinine $5.1 \mathrm{mg} / \mathrm{dL}$, AST $12 \mathrm{U} / \mathrm{L}$, creatinine phosphocinase (CPK) $52 \mathrm{U} / \mathrm{L}$. The patient was started anti-tuberculosis treatment including isoniazid $300 \mathrm{mg} /$ day, rifampicin $600 \mathrm{mg} / \mathrm{day}$, ethambutol and morfazinamide $1500 \mathrm{mg} /$ every other day. In the fifth day, metabolic acidosis was deepened and the patient's clinical status had deteriorated, and BUN was $85 \mathrm{mg} / \mathrm{dL}$, creatinine $4.4 \mathrm{mg} / \mathrm{dL}$, AST $481 \mathrm{U} / \mathrm{L}, \mathrm{CPK} 752 \mathrm{U} / \mathrm{L}$, LDH $1600 \mathrm{U} / \mathrm{L}$. We considered clinical feature of the patient as rhabdomyolysis, after than all drugs were subsequently withdrawn. In the eighth day, CPK levels increased to $9000 \mathrm{U} / \mathrm{L}$ and hemodialysis was started. Then, his myalgia gradually subsided with treatment, CPK declined gradually and returned to normal levels. We restarted other anti-tuberculosis drugs without isoniazid because of active tuberculosis. The patient was monitored closely for rhabdomyolysis by biochemical tests, after starting anti-tuberculosis therapy, CPK levels observed in normal ranges.

INH has been superior bactericidal activity and low toxicity that used as a first-line agent for tuberculosis prophylaxis and treatment. The ingestion of toxic amounts of isoniazid causes recurrent seizures, profound metabolic acidosis, coma and even death $(1,5)$. The toxic effects of INH may lead accumulation of lactic acid and producing an intracellular acidosis that inhibits the myofibrillary proteins is one theory to explain muscle fatigue during treatment of tuberculosis $(6,7)$.

However, there is no enough information about development of rhabdomyolysis, it is possible that the muscle damage may be due to direct injury or metabolic inequalities between energy consumption and energy production by accumulation of acidic consumptions(8) The exact mechanism of rhabdomyolysis caused by isoniazid is largely unknown. There are several possible explanations for the link between isoniazid and rhabodomyolysis. First, isoniazid metabolism is largely carried out by the liver, but may also occur in the kidneys and muscles. Isoniazid can be catalyzed into acetylisoniazid by $\mathrm{N}$ acetyltransferase 2, and further hydrolyzed to toxic acetylhydrazine, isonicotinic acid and its downstream products including toxic acetylated derivatives, ammonia and reactive oxygen species. Alternatively, these toxic metabolites produced from cytochrome P450. These metabolites may directly damage the striated muscle cells via covalent binding, oxidative stress, lipidperoxidation products, mitochondrial dysfunction such as hepatotoxicity, and may lead to accumulation of lactic acid and intracellular acidosis that inhibits the myo-fibrillary proteins predisposing rhabdomyolysis. Second, the pharmacokinetic profile of isoniazid has been changed due to old age and decreased glomerular filtration rate, thereby causing a reduction on clearance of the drug and its metabolites, which increases the risk for rhabdomyolysis. (2, 4-6).

In conclusion, we speculated that the rhabdomyolysis may be a one of the rare side effects of INH therapy. The presence of CKD may lead to development of rhabdomyolysis tendency as well as other side effects in these patients.

References

Panganiban LR, Makalinao IR, Cortes-Maramba NP. Rhabdomyolysis in Isoniazid poisoning. J Toxicol Clin Toxicol. 2001; 39: 143-51

Zheng HS, Yuan WL, Wang JF. Isoniazid-induced rhabdomyolysis in a patient with chronic heart failure: a case report. Chin Med J (Engl). 2010; 123 :

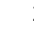

Kurultak I, Altay M, Sanli A, et al. Hemodiyaliz: akut izoniazid zehirlenmesinde yaşam kurtarıcı tedavi. Çağdaş Tıp Dergisi. 2014; 4:157-9.

Topcu I, Yentur EA, Kefi A, et al. Seizures, metabolic acidosis and coma resulting from acute isoniazid intoxication. Anaesth Intensive Care. 2005; 33:

Schwab CE, Tuschl H. In vitro studies on the toxicity of isoniazid in different cell lines. Hum Exp Toxicl. 2003; 22: 607-15

6. Mach J, Huizer-Pajkos A, Mitchell SJ, et al. The effect of ageing on isoniazid pharmacokinetics and hepatotoxicity in Fischer 344 rats. Fundam Clin Pharmacol. 2016; 30: 23-34

Corresponding Author: Mevlut Ceri, MD

Address: Pamukkale University Faculty of Medicine, Department of Nephrology, Denizli, Turkey

Başvuru Tarihi/Received: 23-11-2014

E-mail: $\quad \underline{\text { tscer@yahoo.com }}$

Kabul Tarihi/Accepted: $\quad$ 03-03-2016

Telephone: +902582966000-5671 